\title{
Cystic Lesions of the Pancreas
}

\author{
Julia Mayerle $^{\mathrm{a}} \quad$ Jens Werner $^{\mathrm{b}}$ \\ a Department of Gastroenterology and Hepatology, Ludwig Maximilians-University, Munich, Germany; \\ ${ }^{\mathrm{b}}$ Department of General, Visceral, and Transplantation Surgery, Ludwig Maximilians-University, Munich, Germany
}

The awareness of pancreatic cystic lesions has dramatically increased over the past decades. Due to increasing precision and the more frequent use of modern imaging modalities, cystic lesions of the pancreas are diagnosed more often. They differ in their clinical presentation, morphology, and, most importantly, their risk of malignant transformation.

The diagnostic tool box to define the type of cyst and its potential risk of malignancy has increased over time; however, diagnostic accuracy is still not higher than $80 \%$.

Furthermore, despite the definition of risk factors for malignancy, the differentiation between benign and malignant cysts is still difficult and in many cases impossible. Several guidelines have discussed the management of cystic lesions of the pancreas, although most of the guideline papers are consensus statements rather than evidence-based publications. Moreover, there is still quite a controversy about the best treatment and follow-up regimen. The article by Scholten et al. [1] in this issue of VISCERAL Medicine summarizes the main statements of the first evidencebased guideline on pancreatic cystic neoplasms [2], which was recently published.

The review articles in this issue on biomarkers [3], radiological workup [4], and endoscopy [5] describe the evidence available regarding diagnostics today, while the articles by Beyer et al. [6], Andrianello et al. [7], as well as D'Haese and Werner [8] summarize the latest advances in treatment, including the indications for surgery and the different options of resection. Despite the increasing data on the management of cystic lesions, the controversy regarding the best treatment remains. The risk of developing a malignancy under surveillance has to be balanced against the risk of surgical resection $[6,7]$. The risk of perioperative morbidity and mortality is dependent on the expertise of a surgical center, the amount of surgical cases, and the type of procedures performed. The complication rate and the mortality of resections for cystic lesions of the pancreas are significantly lower if compared to surgical resec- tion for pancreatic cancer since extended resections are rarely needed. Moreover, many reports have been published which demonstrate that the development of pancreatic cancer cannot be avoided in all patients despite close follow-up. Overall, this might be a rare event, and some publications claim that the risk of malignancy in pancreatic cystic lesions is lower than previously reported. Thus, a general practitioner or even a specialized pancreatologist might not observe the development of cancer in many of his patients. In contrast, large surgical centers report more and more often on the development of pancreatic cancer and even unresectable cancers in a significant number of their patients. Therefore, apart from the evidence available, personal experience with the disease and the different treatment options will continue to influence our decision making in daily practice.

In addition, the best way of follow-up of patients with pancreatic cysts is also very controversial and depends on the type of cyst, the potential of its malignant transformation (secondary to risk factors), as well as the age and risk profile of the patient. The follow-up of the increasing amount of patients with pancreatic cysts is time-consuming, expensive, and not well defined. In the 'Interdisciplinary Discussion' chaired by Werner [9], all international experts agree that a blood-based test and biomarkers are needed for better and cost-effective surveillance in the future. The article by Raman and Lennon [3] in this issue also highlights the evidence available today.

Last but not least, as guest editors of this issue on cystic lesions of the pancreas, we would like to express our gratitude and appreciation to all the authors for their outstanding efforts and great contributions.

\section{Disclosure Statement}

A conflict of interest does not exist.

\section{KARGER}

(c) 2018 S. Karger GmbH, Freiburg

Fax +497614520714
Prof. Dr. med. Jens Werner

Klinik für Allgemein-, Viszeral-, Gefäß- und Transplantationschirurgie

LMU Klinikum der Stadt München

Marchioninistraße 15, 81377 München, Germany

jens.werner@med.lmu.de 


\section{References}

1 Scholten L, van Huijgevoort NCM, van Hooft JE, Besselink MG, Del Chiaro M: Pancreatic cystic neoplasms: different types, different management, new guidelines. Visc Med 2018;34:DOI: 10.1159/000489641.

2 European Study Group on Cystic Tumours of the Pancreas: European evidence-based guidelines on pancreatic cystic neoplasms. Gut 2018;67:789-804.

3 Raman A, Lennon AM: Cyst fluid biomarkers - diagnosis and prediction of malignancy for cystic lesions of the pancreas. Visc Med 2018;34:DOI: 10.1159/ 000490137.
Bollen TL, Wessels FJ: Radiological workup of cystic neoplasms of the pancreas. Visc Med 2018;34:DOI: $10.1159 / 000489674$

5 Lévy P, Rebours V: The role of endoscopic ultrasound in the diagnosis of cystic lesions of the pancreas. Visc Med 2018;34:DOI: 10.1159/000489242.

-6 Beyer G, Goni E, Köpke M, D’Haese JG, Werner J, Schirra J, Mayerle J: Management algorithm for cystic pancreatic lesions. Visc Med 2018;34:DOI: 10.1159/ 000489233.

7 Andrianello S, Falconi M, Salvia R, Crippa S, Marchegiani G: Surveillance of cystic lesions of the pancreas: whom and how to survey? Visc Med 2018;34:DOI: $10.1159 / 000489240$.
D'Haese JG, Werner J: Surgery of cystic tumors of the pancreas - why, when, and how? Visc Med 2018; 34:DOI: 10.1159/000489234.

9 Werner J, Belyaev O, Fernández-del Castillo C, Lévy P, Löhr M, Mayerle J, Uhl W: Diagnostic and treatment algorithms of pancreatic cystic tumors (Interdisciplinary Discussion). Visc Med 2018;34:DOI: 10.1159/ 000490817.

\section{KARGER}

(c) 2018 S. Karger GmbH, Freiburg 